\title{
Eniluracil/5-FU Combination Tablet
}

National Cancer Institute

\section{Source}

National Cancer Institute. Eniluracil/5-FU Combination Tablet. NCI Thesaurus. Code

C11252.

A combination tablet of ethynyluracil and fluorouracil. Fluorouracil is an antimetabolite fluoropyrimidine analog of the nucleoside pyrimidine with antineoplastic activity.

Ethynyluracil is an orally-active fluoropyrimidine analog that inhibits dihydropyrimidine dehydrogenase, the rate-limiting enzyme that catabolizes and inactivates 5-fluorouracil in the liver. This may lead to an increase in the bioavailability and, effectiveness of fluorouracil. 